\title{
ERRATUM
}

\section{On homotopy conditions and the existence of multiple equilibria in finite elasticity}

\author{
K. D. E. Post \& J. Sivaloganathan
}

(Printed in volume 127, part 3, pp. 595-614.)

The publishers regret that, owing to a printing error, Figure 6.1 on page 611 is incorrect. The printed version is a duplicate of Figure 5.2. The correct Figure 6.1 is reproduced below.

The publishers and printers apologise for the confusion and inconvenience caused by the error.
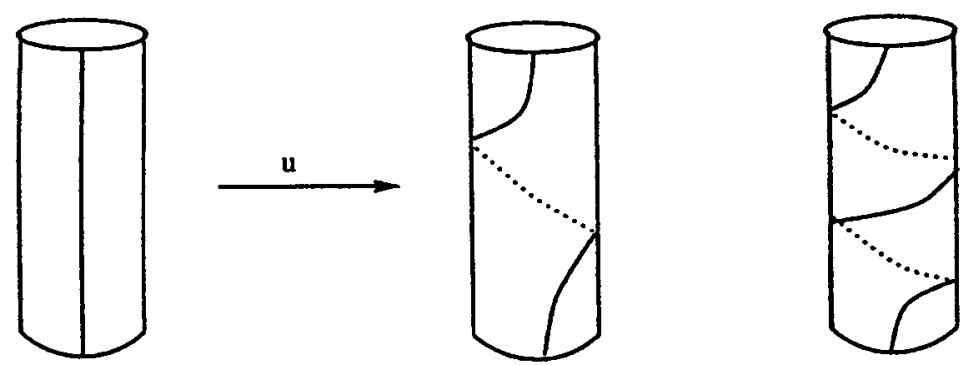

\section{$\mathbf{z}$}

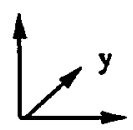

$\mathbf{x}$

Figure 6.1. 